\title{
Excess cause-specific mortality in out-patients with personality disorder
}

\author{
Charlotte Björkenstam, Emma Björkenstam, Bengt Gerdin and Lisa Ekselius
}

\begin{abstract}
Summary
Personality disorders (PDs) are associated with increased overall mortality. In patients hospitalised with a principal diagnosis of PD, this is observed for all clusters and for natural as well as unnatural causes of death. Data from Swedish nationwide registers were used to assess whether this was also true for the majority of patients diagnosed with PDs not severe enough to lead to hospitalisation. There was an increased mortality in all clusters, and for natural as well
\end{abstract}

as unnatural death, also in patients treated as out-patients only, although not to the same extent as in those hospitalised.

\section{Declaration of interest}

None.

\section{Copyright and usage}

(c) The Royal College of Psychiatrists 2015. This is an open access article distributed under the terms of the Creative Commons Non-Commercial, No Derivatives (CC BY-NC-ND) licence.
It is well established that individuals with a personality disorder (PD) have higher overall mortality and a shorter life expectancy compared to the general population. ${ }^{1-4}$ These mortality figures are, however, largely based on investigations in patients given inpatient care or without differentiating between in- and out-patient care. In line with this, we have recently shown ${ }^{5}$ that individuals hospitalised with a primary diagnosis of PD have an increased mortality both overall, and in all clusters, and for natural as well as unnatural causes of death.

There are a number of arguments indicating that those hospitalised because of PD may represent a subgroup of patients with more severe problems in personality functioning, making uncritical extrapolation to patients who are not treated as inpatients impossible. First, hospital admission is related to more complex personality pathology. ${ }^{6}$ Second, the gender distribution and the distribution between clusters observed in the nationwide Swedish cohort, with a preponderance of females and dominance of Cluster B patients and those defined as 'other PD', 5 differed from what was expected from global health survey data where there is a preponderance of males, and a fairly equal distribution between clusters. ${ }^{7}$ Furthermore, the group 'other PD' reasonably includes individuals with more severe personality pathology. Finally, the fact that some persons with PD actually seek care, while others reject care, ${ }^{9}$ affects generalisability from in-patient data.

In the present study we extracted data from nationwide Swedish registers in an attempt to reveal whether overall and cause-specific increased mortality were increased in persons treated as out-patients only and, if so, to compare this increase in mortality with that in individuals also treated as in-patients.

\section{Method}

The unique personal identity number assigned to each Swedish resident ${ }^{10}$ was used to link information from two populationbased registers. All individuals undergoing either in-patient care or specialised out-patient care in Sweden between 2001 and 2011 with a primary diagnosis of PD were identified using the National Patient Register. This register includes all individuals admitted to any psychiatric or general hospital and has almost complete coverage. ${ }^{11}$ Since 2001 , the first year of our cohort, all out-patient visits to specialised care have been included. The patients were divided into two groups, those given out-patient care only, and those given in-patient care with or without also receiving out-patient care. The patients were classified according to ICD-10 as follows: Cluster A: Paranoid (F600), Schizoid (F601); Cluster B: Antisocial/dissocial (F602), Emotionally unstable/ explosive/borderline (F603), Histrionic (F604); Cluster C: Anankastic (F605), Anxious (avoidant) (F606), Dependent (F607); and unclustered: Other specific (F608) and Unspecified (F609). Patients not included in Cluster A, B or C were classified as 'other PD'. As it is very rare to diagnose individuals under the age of 15 , or elderly individuals, with $\mathrm{PD}$, we excluded those younger than 15 years and older than 64 years, and also those with a prior hospitalisation for PD before 2001. Our cohort comprised 33196 individuals (data supplement, Fig. DS1).

The Cause of Death Register was used to obtain information on cause of death. This register contains information on all deceased Swedish residents since $1952 .{ }^{12}$ The patients were followed from the date of first discharge or date of first outpatient visit until death or until the end of the follow-up period on 31 December 2011, i.e. for up to 10 years. The underlying causes of death were also coded according to ICD-10.

The number of expected deaths was calculated by multiplying number of person-years at risk by 5 -year age group and calendaryear specific mortality rates in the general population. The standardised mortality rates (SMRs; i.e. the ratio between the observed number of deaths and the expected number of deaths during the follow-up period), were used as a measure of risk. SMRs were calculated with $95 \%$ confidence intervals, assuming that the observed number of deaths in each group follows a Poisson distribution. In running text SMRs are given with 95\% CIs within brackets. SAS v. 9.2 (SAS Institute Inc., Cary, NC, USA) was used.

The study was approved by the Regional Ethical Review Board in Stockholm, Sweden.

\section{Results}

In total, 21136 women and 12060 men with a primary diagnosis of PD were treated at least once between 2001 and 2012 (data supplement, Table DS1). The vast majority ( $70 \%$ of individuals) were treated in out-patient care only.

Cluster B PD was by far the most common in women, as $61 \%$ of female patients in in-patient care and $44 \%$ in out-patient care were diagnosed with a Cluster B diagnosis. For men, diagnoses derived from the group 'other PD' were most common in both inand out-patient care. 
Table 1 Absolute numbers of deaths and SMRs with $95 \% \mathrm{Cls}$ for all cases in women and men

\begin{tabular}{|c|c|c|c|c|}
\hline & \multicolumn{2}{|r|}{ Women } & \multicolumn{2}{|r|}{ Men } \\
\hline & $n$ & SMR (95\% Cl) & $n$ & SMR (95\% Cl) \\
\hline \multicolumn{5}{|c|}{ In-patient care with or without out-patient care } \\
\hline Total & 311 & $10.8(9.7-12.1)$ & 310 & $9.6(8.6-10.7)$ \\
\hline Natural & 91 & $4.0(3.2-4.9)$ & 115 & $3.5(3.0-4.3)$ \\
\hline Cancer & 20 & $1.5(1.0-2.4)$ & 20 & $2.3(1.5-3.5)$ \\
\hline Mental & 3 & $8.2(2.7-25.6)$ & 10 & $11.4(6.1-21.1)$ \\
\hline Cardiovascular & 31 & $8.1(5.7-11.5)$ & 46 & $5.8(4.4-7.8)$ \\
\hline Respiratory & 6 & $6.5(2.9-14.6)$ & 3 & $3.4(1.1-10.4)$ \\
\hline Gastrointestinal & 6 & $6.3(2.8-14.0)$ & 8 & $5.2(2.6-10.4)$ \\
\hline Other & 25 & $6.9(4.6-10.2)$ & 28 & $7.4(5.1-10.7)$ \\
\hline Unnatural & 220 & $37.7(33.0-43.0)$ & 195 & $22.5(19.5-25.8)$ \\
\hline Suicide & 149 & $55.0(46.8-64.6)$ & 120 & $35.8(29.9-42.8)$ \\
\hline $\begin{array}{l}\text { Deaths with } \\
\text { undetermined } \\
\text { intent }\end{array}$ & 35 & $50.6(36.3-70.4)$ & 28 & $28.2(19.5-40.9)$ \\
\hline Traffic accidents & 5 & $5.9(2.5-14.2)$ & 4 & $2.9(1.1-7.8)$ \\
\hline Other & 31 & $19.5(13.7-27.7)$ & 43 & $14.5(10.7-19.5)$ \\
\hline \multicolumn{5}{|l|}{ Out-patient care only } \\
\hline Total & 295 & $3.7(3.3-4.1)$ & 390 & $3.8(3.4-4.2)$ \\
\hline Natural & 145 & $2.1(1.8-2.5)$ & 173 & $2.2(1.9-2.6)$ \\
\hline Cancer & 54 & $1.3(1.0-1.8)$ & 36 & $1.2(0.9-1.7)$ \\
\hline Mental & 4 & $4.0(1.5-10.7)$ & 7 & $2.4(1.2-5.1)$ \\
\hline Cardiovascular & 39 & $3.3(2.4-4.5)$ & 58 & $2.2(1.7-2.8)$ \\
\hline Respiratory & 15 & $5.4(3.2-8.9)$ & 9 & $3.1(1.6-6.0)$ \\
\hline Gastrointestinal & 9 & $3.0(1.6-5.8)$ & 18 & $3.5(2.2-5.5)$ \\
\hline Other & 24 & $2.5(1.7-3.8)$ & 45 & $3.8(2.8-5.1)$ \\
\hline Unnatural & 150 & $12.6(10.7-14.7)$ & 217 & $9.0(7.9-10.3)$ \\
\hline Suicide & 97 & $17.6(14.5-21.5)$ & 103 & $11.0(9.0-13.3)$ \\
\hline $\begin{array}{l}\text { Deaths with } \\
\text { undetermined } \\
\text { intent }\end{array}$ & 25 & $16.7(11.3-24.7)$ & 40 & $14.8(10.9-20.2)$ \\
\hline Traffic accidents & 4 & $2.7(1.0-7.1)$ & 9 & $2.5(1.3-4.8)$ \\
\hline Other & 24 & $6.9(4.6-10.2)$ & 65 & $7.7(6.1-9.9)$ \\
\hline
\end{tabular}

Altogether 606 women and 700 men died during the followup period (Table 1). This corresponded to 5 and $10 \%$, respectively, of those given in-patient care and 2 and $4 \%$, respectively, of those given out-patient care.

There was an increased all-cause SMR in both genders, both in in- and out-patient-treated patients with PD (Table 1). The increase was more pronounced in those treated as in-patients than in those only treated as out-patients, with SMR of 10.8 in women and 9.6 in men $v .3 .7$ and 3.8, respectively.

There was also an increased all-cause SMR for all clusters, both in in- and out-patient-treated patients with PD (Table DS2). The highest all-cause SMRs were observed for Cluster B in both genders, with a value of 13.3 in women and 12.8 in men given in-patient care, v. 4.3 in women and 5.7 in men given out-patient care.

The SMR was increased both for natural causes of death, 10.8 in women and 9.6 in men in in-patient care $v .2 .1$ and 2.2, respectively in out-patient care, and for unnatural causes of death, 37.7 in women and 22.5 in men $v .12 .6$ and 9.0 respectively (Table 1). In particular, SMR for suicide was 55.0 in women and 35.8 in men in in-patient care $v .17 .6$ and 11.0 in out-patient care.

\section{Discussion}

This investigation, where patients were followed for up to 11 years, shows that the increased SMRs for all clusters of PD previously shown for persons treated as in-patients ${ }^{5}$ are also seen in those persons who have undergone out-patient care only. The
SMRs reported here are actually even higher than in the previous study. As most deaths occur less than 10 years after the index episode, ${ }^{5}$ the longer follow-up in the previous study, up to 25 years, may explain that difference.

The observations reported here refute arguments that only those persons with a PD severe enough to motivate in-patient treatment are burdened by an increased mortality risk. This has important practical implications, as most patients with clinical problems related to a PD are treated as out-patients only, in this sample $70 \%$.

On the other hand, the death risk in those treated as outpatients only is clearly less than in those who are given in-patient care, supporting the concept of a difference in clinical severity between these groups. ${ }^{6}$

The strength of this study is the use of population-based national registers with high coverage. The limitation is that the formal diagnoses required by the Swedish healthcare system are given at the discretion of the treating physician which is why its scientific validity in individual cases can be questioned.

\section{Charlotte Björkenstam, PhD, Department of Clinical Neuroscience, Karolinska Institutet, Stockholm, Sweden; Emma Björkenstam, PhD, Department of Public Health Sciences, Division of Social Medicine, Karolinska Institutet, Stockholm, Sweden; Bengt Gerdin, MD, PhD, Department of Surgical Sciences, Uppsala University, Uppsala, Sweden; Lisa Ekselius, MD, PhD, Department of Neuroscience, Psychiatry, Uppsala University, Uppsala, Sweden \\ Correspondence: Lisa Ekselius, Department of Neuroscience, Psychiatry, Uppsala University, Uppsala University, Uppsala University Hospital, 75185 Uppsala, Sweden. Email: lisa.ekselius@neuro.uu.se \\ First received 5 Feb 2015, final revision 8 Jul 2015, accepted 9 Jul 2015}

\section{References}

1 Harris EC, Barraclough B. Excess mortality of mental disorder. Br J Psychiatry 1998; 173: 11-53.

2 Grigoletti L, Perini G, Rossi A, Biggeri A, Barbui C, Tansella M, et al. Mortality and cause of death among psychiatric patients: a 20-year case-register study in an area with a community-based system of care. Psychol Med 2009; 39: 1875-84.

3 Fok ML, Hayes RD, Chang CK, Stewart R, Callard FJ, Moran P. Life expectancy at birth and all-cause mortality among people with personality disorder. J Psychosom Res 2012; 73: 104-7.

4 Nordentoft M, Wahlbeck K, Hallgren J, Westman J, Osby U, Alinaghizadeh H, et al. Excess mortality, causes of death and life expectancy in 270,770 patients with recent onset of mental disorders in Denmark, Finland and Sweden. PLOS One 2013; 8: e55176.

5 Björkenstam E, Björkenstam C, Holm H, Gerdin B, Ekselius L. Excess causespecific mortality in in-patient-treated individuals with a diagnosis of personality disorder: a 25-year nationwide population-based study. Br J Psychiatry 9 Jul 2015 (doi: 10.1192/bjp.bp.114.149583).

6 Yang $M$, Coid J, Tyrer P. Personality pathology recorded by severity: national survey. Br J Psychiatry 2010; 197: 193-9.

7 Huang Y, Kotov R, de Girolamo G, Preti A, Angermeyer M, Benjet C, et al. DSM-IV personality disorders in the WHO World Mental Health Surveys. Br J Psychiatry 2009; 195: 46-53.

8 Verheul R, Bartak A, Widiger T. Prevalence and construct validity of Personality Disorder Not Otherwise Specified (PDNOS). J Pers Disord 2007; 21: 359-70.

9 Tyrer $\mathrm{P}$, Mitchard S, Methuen C, Ranger M. Treatment rejecting and treatment seeking personality disorders: Type R and Type S. J Pers Disord 2003; 17: 263-8.

10 Ludvigsson JF, Otterblad-Olausson P, Pettersson BU, Ekbom A. The Swedish personal identity number: possibilities and pitfalls in healthcare and medical research. Eur J Epidemiol 2009; 24: 659-67.

11 Ludvigsson JF, Andersson E, Ekbom A, Feychting M, Kim JL, Reuterwall C, et al. External review and validation of the Swedish national inpatient register. BMC Public Health 2011: 11: 450

12 National Board of Health and Welfare. Causes of Death 2011. National Board of Health and Welfare, 2012 